Article

\title{
Knowledge, Information, and Views of Climate Change: An Examination of Coastal Stakeholders along the Gulf of Mexico
}

\section{James W. Stoutenborough ${ }^{1}$ and Arnold Vedlitz ${ }^{2, *}$}

1 Department of Political Science, Idaho State University, 921 S 8th Ave, Pocatello, ID 83209, USA;

E-Mail: james.stoutenborough@isu.edu

2 The Bush School of Government and Public Service, Texas A\&M University, 4350 TAMU, College Station, TX 77843-4350, USA

* Author to whom correspondence should be addressed; E-Mail: avedlitz@tamu.edu; Tel.: +1-979-845-2929.

Received: 10 September 2015 / Accepted: 10 November 2015 / Published: 18 November 2015

\begin{abstract}
The ability to understand complex issues is essential to adequately evaluate risk and policy alternatives. Stakeholders are more likely to understand and influence these issues. While stakeholders that specialize in coastal regions have many issues that demand their attention, there are a few that potentially affect everyone within this community. We utilize in-depth interviews to examine climate change attitudes, and the influence of knowledge, information, and institutions within a sample of stakeholders along the Gulf Coast in Florida, Texas, and Louisiana. Our analysis is the first to reveal that institutional forces may influence climate change attitudes for members of that institution. Furthermore, we learn that different sources of information directly influence these attitudes.
\end{abstract}

Keywords: stakeholder influence; climate change; information sources; knowledge deficit model

\section{Introduction}

The ability to understand complex, scientific issues is essential for anyone to adequately evaluate the potential risk and policy alternatives associated with an issue. Due to the complexities associated with understanding ecosystems, currents, erosion, pollution, and the interaction of all of these in the intricacies of coastal areas, it is understandable that the public often lacks the knowledge required for informed decision making. In these complex environments, stakeholders emerge from various fields and 
professions to take the lead on issues like coastal management. These stakeholders develop a better understanding of the issues within their issue domains, which enables them to potentially influence the decision-making process.

Stakeholders who specialize in coastal management have many issues that demand their attention at any given time. These issues may be local or even regional in nature, but rarely are there issues that can truly be described as global, in that it will affect everyone within this stakeholder community. One such global issue is climate change. From risks like rising sea levels to increased water temperatures, stakeholders within this community should consider climate change and the impact that it will have on their coastal areas [1].

Little is understood of the climate change beliefs and attitudes of stakeholders within this community. Stakeholders include coastal industry and fishermen, government employees, and interest group leaders. With their potential to influence public policy, it is essential that we understand what their views might be, and how these views are influenced. To accomplish this task, we conducted in-depth interviews with stakeholders along the Gulf of Mexico within three states-Texas, Louisiana, and Florida - in the United States on issues related to climate change. We believe that the attitudes and beliefs of these stakeholders likely reflect the views of stakeholders around the world because of the global nature of climate change and social science literature has begun to find that the institutional, informational, and societal influences on beliefs are similar regardless of location [2], though the specifics may differ.

This project seeks to understand the influence of knowledge, information, and institutions on stakeholder acceptance of the reality of climate change. As the scientific community continues to solidify its consensus views about the reality of climate change [3,4] it is important to understand if the stakeholders that influence the coastal management accept this scientific conclusion. If these stakeholders are skeptical about climate change, they are less likely to advocate for policies that would promote mitigation and adaptation, which may help to explain the lack of policy action in countries like the United States. They may be less likely to adapt, which could have catastrophic implications for ecosystems, both in the United States and beyond.

The focus on these three influences is relatively unique within the study of climate change attitudes. We are unaware of previous research examining whether different types of institutional norms cause stakeholders from those institutions to perceive climate change differently. Drawing from the literature on the institutional analysis and development framework, we seek to determine the extent to which institutions influence behavior. Information regarding where individuals obtain their information and evaluations of knowledge are rare within the extant literature. Combined, this project should allow new insight into the determinants of climate change attitudes.

This project proceeds as follows. We begin with a review of the pertinent literature to help us better understand the relationship between knowledge, information, institutions, and climate change views. We develop an analytical approach specifically to examine this relationship. Finally, we explore the results of our analysis and discuss the implications. In the end, our examination reveals an interesting dynamic between knowledge, information, and institutional influences on acceptance of the reality of climate change. 


\section{The Knowledge-Deficit}

The Latin phrase scientia potentia est, or "knowledge is power," exemplifies the basic principle of the knowledge-deficit model (KDM). This model argues that through research, education, and experience scientists generate a great deal of knowledge about specific subjects. For instance, climate scientists have generated volumes of studies cataloging the effects of greenhouse gases on global temperatures. KDM suggests that this expertise equips scientists with the ability to better identify the problems related to their area of interest. For example, climate scientists warn that, if unabated, rising global temperatures can lead to thermal expansion of sea water and the melting of the polar ice caps, particularly land-based ice, which would cause significant increases in sea levels (for a comprehensive overview of this research see [1]). This, in turn, could have a devastating impact on coastal cities and vulnerable environments such as the Everglades [1].

With a better understanding of the subject and an improved chance of recognizing problems, KDM suggests that scientists are also better situated to identify policy solutions. To solve a problem, one must understand the problem. Scientists, KDM asserts, are in the best position to understand the nature of the problem. With this understanding, they are able to identify causal mechanisms. Once identified, policy solutions can be designed to maximize the likelihood of correcting the causes of the problem or adapting to the problem [5].

The implicit comparison to scientists is with the general public. KDM claims the public does not have the knowledge or understanding of the scientists. Simply, scientists know things the public does not. Accordingly, for supporters of KDM, the public is less able to identify problems, determine policy solutions, and ascertain adequate resource allocation. For supporters of KDM, this knowledge gap has several political implications. If the public is unable to fully grasp the situation, it is unreasonable to expect that they will come to the correct, or, at the very least, most efficient policy solution. Additionally, if the public lacks a clear understanding of the problem, they are going to be less likely to support policy proposals [6], particularly if those proposals carry rather large costs.

The expectation is that to get the public to understand the issue in the same manner as the scientists this knowledge gap must shrink. As the public becomes more knowledgeable, KDM predicts, they are more likely to view the issue the same way the scientists view the issue, which should increase the likelihood that the public will reach similar problem identification, policy solution, and resource allocation conclusions. When the public is confused about an issue, KDM says they will benefit from an explanation from scientists. All of these precepts of KDM either implicitly or explicitly argue that a small segment of the population understands an issue better than the majority of the population, and that to get the majority to see things the way scientists see them, the majority must be educated to shrink the knowledge gap.

Consistent with the above and when thought of in terms of costs versus benefits associated with risk, Hansen, Holm, Frewer, Robinson, and Sandøe [7] (p. 112) outline the four assumptions of KDM.

(1) Subject to acceptable levels of risk, the optimization of productivity is a commonly shared value in modern societies.

(2) The acceptable levels of risk associated with optimal productivity are universally, or at least widely, agreed. 
(3) Scientific knowledge is the most effective, and hence desirable, basis on which to improve both the production of goods and risk control, and therefore, scientific evidence should be the primary guide in risk management.

(4) If the public does not comply with the advice and recommendations of scientific experts, this is because they have a poor understanding of the scientific reasoning informing that advice, i.e., a "knowledge deficit".

In other words, Hansen et al. [7] are suggesting that the more public knowledge reflects scientific knowledge, the more likely there will be opinion and policy congruence between scientists and the public and that "better" decisions will be made. Within climate change, KDM suggests that those with more knowledge would be more willing to accept climate change as a reality, accept some semblance of responsibility for the problem, and have greater perceptions of risk stemming from climate change $[8,9]$.

However, the more complex and complicated an issue, the greater the likelihood the public will incorrectly interpret the information that is provided because they seek overly simplified explanations of these complex problems. For instance, as the public becomes more knowledgeable it may overestimate the risk associated with a problem [7]. Nuclear energy is an example of this overestimation of risk, in terms of the likelihood of a meltdown. The nuclear industry, the recent unprecedented events in Japan notwithstanding, has been a relatively stable and safe source of electricity. However, following the Three Mile Island and Chernobyl incidents, the public has considerably overestimated the risk of catastrophic failure [10].

On the other hand, as Kellstedt, Zahran, and Vedlitz illustrated [8], there can also be an underestimation of risk. With climate change, this has meant that the U.S. has avoided adopting policies that would substantially curb greenhouse gas emissions because of the impact of these policies on the economy, or other previously outlined aspects that cause the public to not accept the scientific consensus on climate change, outweigh the potential risks associated with climate change [11]. In the first example, the public has drastically overestimated the risk of meltdown, and would rather obtain their energy from other sources, even if those sources pollute the air or are more expensive. In the second, many may have underestimated the risk, and would rather not address the potential ramifications of climate change. In other words, "those who perceive the risk associated with something as high should be more likely to oppose policies that would increase that risk, and, conversely, support policies that decrease this risk" [12].

If increased levels of knowledge within the public do not automatically, and for all citizens, increase the likelihood of opinion congruence with scientists, are there some for whom KDM does work better? If so, who and why? Kempton [13] argues that the general public has a tendency to not fully understand climate change, and previous examinations of the knowledge-deficit model, those that found the mis-estimations of risk, relied on national public opinion polls. If the general public does not fully understand climate change, then perhaps we should examine a more attentive sub-group of the population to determine if KDM could apply under different conditions.

In situations like this, where the public is largely ignorant of the issue, stakeholders establish themselves because they are able to develop a better understanding of the issue domain. Policymakers, then, cannot rely upon the public for guidance, which causes them to turn to these stakeholders for input. However, we know very little about coastal stakeholders, let alone their views on, or understanding of, climate change. We would expect that stakeholders would be more knowledgeable than the public 
because they are more likely to be invested in the issue. Therefore, the expectations of KDM ought to apply well to this group. The discussion above leads us to expect the following:

H1: Stakeholders that are more knowledgeable about climate change are more likely to accept the scientific assertions about climate change.

\section{Information Sources}

While the amount and type of knowledge is an important influence on attitudes and behavior, the source of information is an intervening factor that cannot be ignored. Neuman, Just, and Crigler [14] developed a theoretical framework that emphasizes that we are active participants in the news communication process. They argue that our learning reflects the specific characteristics of the medium, mode, and message that to which we expose ourselves.

The medium characteristics are particularly important when examining stakeholders because these individuals should have an incentive to expose themselves to many more sources of information than the general public. For instance, a stakeholder could seek information on climate change from governmental reports, peer-reviewed academic research, non-governmental organization (NGO) reports, popularize science sources, or the traditional news media. According to the controlled experiment of Neuman et al. [14] on the impact of different media sources, the type of medium that has the biggest influence on opinion differs depending upon the issue examined.

Mode characteristics are also important. The mode refers to the way the information is presented, whether audio, visual, or both. It is possible that a stakeholder has learned through conversations with professionals or scientists with first-hand knowledge concerning climate change. If so, it is possible that these individuals will have a different view of climate change than those who learned from the print sources.

Finally, the message, or information conveyed, is going to differ depending upon the source. If one were to rely heavily on information produced by the EPA, their views toward climate change are likely to be different from someone who relies on information from for-profit research outlets. Different sources are going to have different goals that they want to achieve-which is where the more traditional agenda setting, priming, and framing effects come in to play-and this is likely to influence their message in some manner. For instance, environmental NGOs are likely to only produce materials that support their advocated views on the environment. Likewise, business and industry sources are likely to downplay the importance of climate change because they do not want more governmental regulations. This discussion leads us to the following expectation.

$\mathrm{H} 2$ : Stakeholder assessments of climate change will differ based upon the source of the information relied upon.

\section{Institutions}

Ostrom [15] argues that institutional norms and rules influence the behavior of individuals within those institutions. Research into institutional norms, rules, and strategies appear to focus largely on micro-level institutions and operational-level decisions [16,17]. However, there is another approach to understanding institutions that emphasizes their role at the macro level [18,19]. This macro-level institutional approach is characterized by a focus on constitutional structures. 
When attempting to control for the influence of institutional norms and rules on attitudes, approaching institutions in this macro-level manner is advantageous. It is often problematic to identify where micro-level institutions begin and end [15]. While it may be difficult to identify and measure a micro-level institution, it ought to be considerably less difficult to identify and measure a macro-level institution, due largely to the generalizations that are needed to create norms, rules, and strategies that are consistent with those found in the micro-institutions they encompass. This process benefits from the loose nature of these micro-level institutions because membership can overlap between micro-level institutions, which better allows for macro-level norms, rules, and strategies to be developed.

In addition to being separate constitutional structures, there are several differences between the different levels of government, which are likely to influence their rules and norms. First, the national government sits atop the general hierarchy of governments followed by state governments, county/parish governments, and finally city governments. Constitutionally, the Supremacy Clause establishes that the national government is the highest form of government in the country, and Dillon's Rule outlines the power structure for local governments within states [20]. Under this system, local governments tend to have few independent powers since they are creatures of the state [21]. Taken as a whole, these differences and characteristics ought to influence the way the different levels of governments behave. These characteristics are unique to each level of government, which ought to create macro-level norms within each group. Accordingly, these norms could influence attitudes about climate change.

While expectations of differing macro-level norms between the different levels of government may not have been initially apparent, these institutional norms ought to be obvious when comparing non-governmental institutions. For instance, the macro-level norms of institutions that harvest natural resources are likely to be different from the macro-level norms of non-governmental organizations that focus their attention of specific environmental goals. Often these two institutions are in constant disagreement and battle in the courts to determine which institution's interpretation of the law is correct. Likewise, there should be clear macro-level norm differences between profit-seeking institutions and the federal government, and these differences ought to influence attitudes. Consequently, we expect the following:

H3: Stakeholder assessments of the scientist assertions on climate change will differ based on the institutional norms of the organization to which they belong.

\section{Analytical Strategy}

To examine the relationship between these influences and beliefs about climate change, we utilize in-depth interviews of estuary and coastal stakeholders. These interviews were part of a larger project seeking to understand the roles of stakeholders in addressing potential climate change impacts (Interviews covered a wide range of topics, including climate change salience, potential stressor impacts, decision making networks, information use, and information gaps). By focusing on more attentive stakeholders, we hope to avoid the concerns about the public's understanding of climate change that Kempton [13] expressed. Stakeholders are decision makers in key groups that play an important role in coastal areas likely affected by climate change impacts.

Our interviews were conducted from September 2004 through February 2005 in three areas along the U.S. Gulf Coast. These three areas were chosen because of their diversity and they represent three 
distinct regions along the Gulf Coast. Interviews were conducted in the Apalachicola Bay area in Florida, the Barataria-Terrebonne Watershed in Louisiana, and Galveston Bay in Texas. Using a quasi-snowballing approach, groups were identified as stakeholders, and respondents were randomly selected from within these groups. Stakeholder groups were identified using a variety of approaches, including documents from local bodies such as planning commissions, meeting notes from relevant bodies, literature/reports from interest groups in each location, and web content for organizations. These groups included associations, government officials, resource harvesting organizations, non-governmental organizations, and profit-seeking organizations (e.g., fisheries). This process resulted in 146 cases for this project.

The dependent variable is based on the objective evaluation of the respondent's discussion concerning their acceptance of climate change. Respondents were coded as fully accepting climate change, exhibiting a mixed acceptance, or not accepting climate change. Those that were identified as fully accepting climate change both accepted that climate change was real and were supportive of taking what scientists commonly refer to as the necessary steps to address the problem. Those exhibiting a mixed acceptance accepted that climate change was a real problem, but they did not agree with the urgency or the policy solutions offered by scientists. Finally, those identified as not accepting climate change did not believe that climate change was occurring; therefore, there was no need for any policy solutions. From this, we assigned an order to the classifications, which resulted in all respondents identified as not accepting climate change coded 0 , those expressing a mixed acceptance coded 1 , and those fully accepting climate change coded 2 .

There were six respondents that were identified as not accepting climate change, twenty-eight exhibiting a mixed response, and one hundred and twelve that fully accepted climate change. These results are not particularly surprising considering stakeholders are more likely to be attentive to the climate change issue than the rest of the population. Additionally, it may be important to note that we did not differentiate between stakeholders' levels of acceptance of the reality of climate change by subdividing their responses based upon the specifics of this acceptance. In other words, we did not categorize acceptance that climate change was caused by human behaviors, though many stakeholders did speak to this. We chose not to subdivide this variable because we did not ask specific questions on these issues, and we felt it would be inappropriate to subdivide based on incomplete information.

When the dependent variable is coded using this process, the most appropriate analytical tool is an ordered logit. This coding scheme has an advantage of being intuitive as well. An individual who has never been exposed to anything regarding climate change or who does not believe any of the research concerning climate change is unlikely to believe that it is occurring or that it is a concern, thus they view the situation with zero risk. As the individual becomes more familiar with the topic, they may begin to accept climate change, but not all aspects of the science or policy prescriptions, which would move them into a stage between full acceptance and no acceptance. Finally, an individual could become convinced that climate change was a serious risk, and that action must be taken to address the problem, which would represent the highest level of risk perception and would be coded a two.

To examine H1, we need to test for the level of knowledge that an individual might have concerning climate change. KDM posits that those with greater knowledge are going to be more likely to have opinions that are congruent with the position of scientists. Due to the nature of our in-depth interviews, we have an advantage over most KDM examinations because we were able to identify respondents that 
had a high level of knowledge about the relationship between climate change and the temperature, precipitation, and/or sea level changes associated with it. Because it was clear that there could be three different types of knowledge of climate change demonstrated by the respondents, we were able to create three very specific measures of knowledge. Through these in-depth interviews, respondents that demonstrated detailed knowledge of the relationship between climate change and temperatures were coded one, and others were coded zero. This coding approach was also applied to demonstrations of precipitation and sea level change knowledge (The interviews consisted of open-ended, free-flowing questions that averaged an hour and a half each. These interviews were audio recorded. Full transcriptions were created, and the data used in this analysis was coded based on the transcripts. For a full explanation of the survey and coding processes, please refer to Vedlitz et al. [22]).

Recall, Neuman et al. [14] discuss the importance of the medium, mode, and message on opinions and attitudes. It is possible that the source of information has a mediating impact on accepting the scientific position on climate change. $\mathrm{H} 2$ expects that different sources of information are going to have an impact on the acceptance of the scientific position on climate change. Each variable was coded 1 when a respondent indicated that they relied upon that type of source and 0 otherwise.

$\mathrm{H} 3$ presented our expectations for the influence of institutions on attitudes. Our approach necessitates thinking of institutional norms at the macro level, which would suggest that there may be norms associated with similar types of institutions that would cause a respondent to be more willing to fully accept the scientific position on climate change, or less willing to fully accept. For instance, respondents that may have worked for the EPA, NOAA, or DOE would all be coded to the macro institution of the federal government. Similarly, respondents affiliated with the Sierra Club, Green Peace, or the Environmental Defense Fund were coded to be in the macro institution of NGOs with broad environmental goals, while groups like RealClimate or the Climate Institute would be coded to belong in the NGOs with specific environmental goals category. Because our sample consists of stakeholders, the influence of institutional norms may be greater than we would expect to find within the general public. Each of the macro institutions the respondents are affiliated with is coded as a dichotomous control variable representing if the respondent was a member or not. We generally expect that there will be a difference between institutional norms that will influence acceptance of climate change.

Under normal circumstances we would want to control for the normal battery of demographic characteristics for the respondents - political ideology, party identification, income, education, etc. Unfortunately, due to the nature of the larger project and the types of questions asked, these characteristics were not recorded in order to gain access to many of the participants. This is a community for which demographic information could allow one to identify specific participants (the implications and concerns associated with this are examined in the discussion section below). Because these demographic questions were unavailable, we create a proxy for one of these characteristics by controlling for the influence of scientific training.

While direct education measures are unavailable, respondents were identified as having scientific training. To have scientific training, one must have additional educational training. While this may not mean that they have graduated college, it does suggest a more specific education than those who do not have this training. This control has the added benefit of being closely associated with climate change. Therefore, we anticipate that those with scientific training will be more likely to fully accept the 
scientific position on climate change. The scientific training variable is coded 1 if they had the training and 0 if they did not.

Finally, there may be differences between respondents resulting from differences between these three states. To control for these differences, we created a dummy variable to represent respondents from Florida, and another for respondents from Louisiana. Respondents from these states will be compared to respondents from Texas. Figure 1 provides a visualization of the distribution of stakeholders for each of our independent variables as well as the dependent variable.

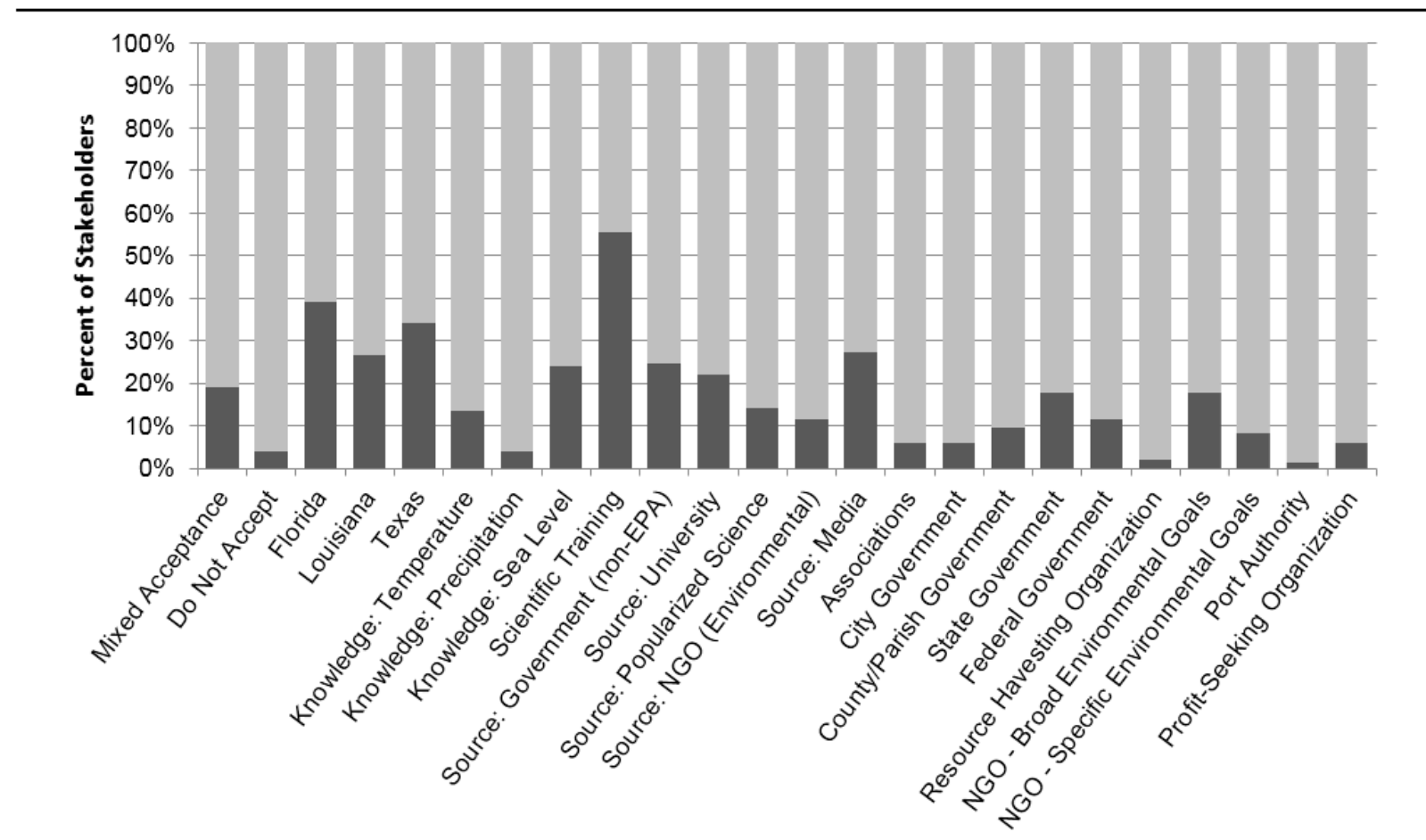

Source: Compiled by authors.

Figure 1. Distribution of responses to the independent and dependent variables.

\section{Results}

What influences the views of coastal stakeholders along the Gulf Coast? To answer this question, we present the results of an ordered logit analyses of stakeholder acceptance of climate change. To provide context to this examination, Figure 2 depicts the distribution of stakeholder acceptance of climate change. The results of our statistical analysis are presented in Table 1.

The analysis provides mixed results for all three hypotheses. Not surprisingly, H1 is confirmed by the influence of knowledge about sea levels, which suggests that coastal stakeholders with more knowledge about the relationship between sea levels and climate change were more likely to accept climate change and the necessary policy solutions. However, we were unable to find support for H1 when applied to the link between temperatures and climate change. Unfortunately, we were unable to actually model the third measure of knowledge, the one between precipitation and climate change, because every respondent that demonstrated knowledge on this topic fully accepted climate change. Technically, this would confirm $\mathrm{H} 1$. 


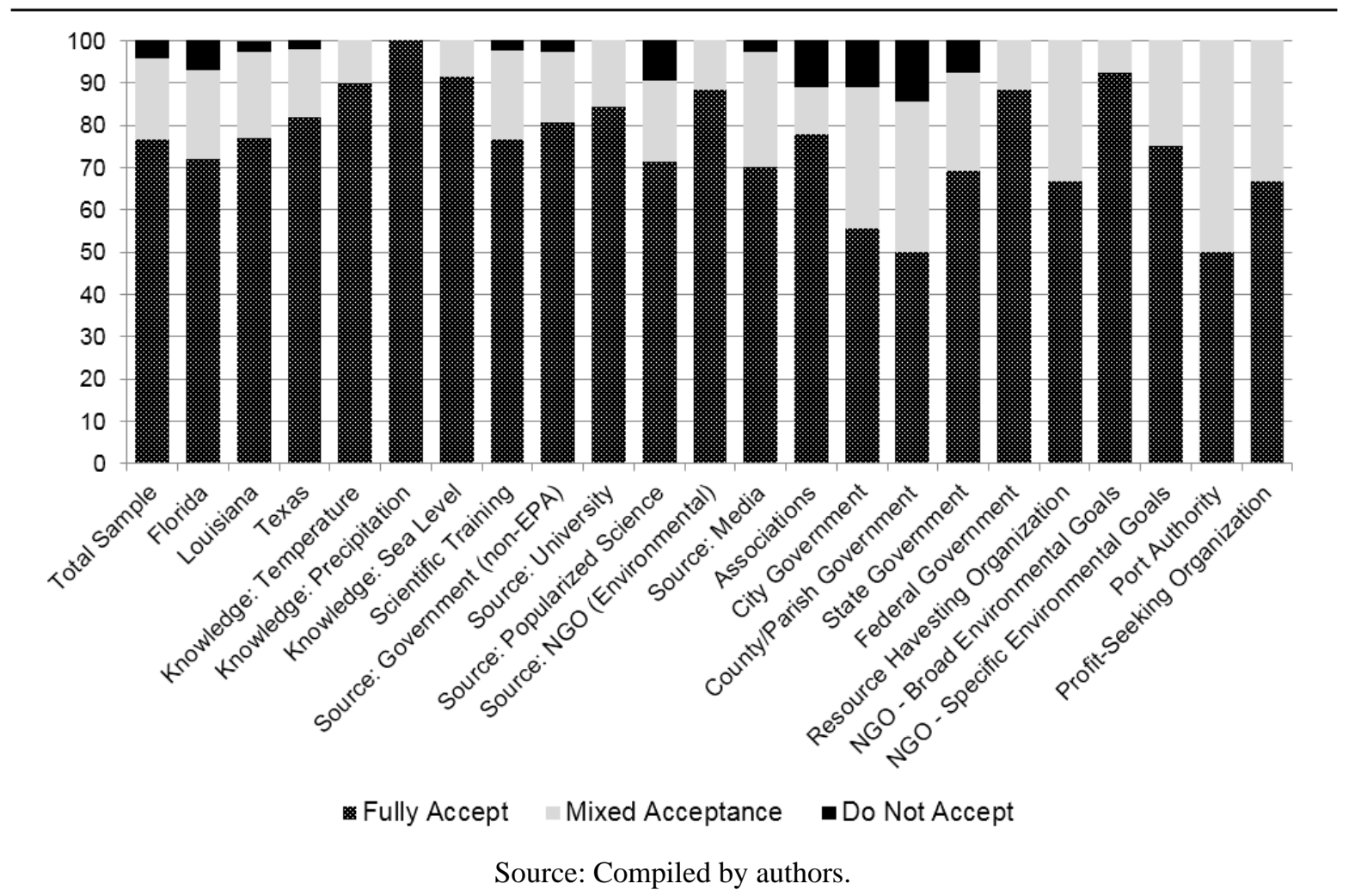

Figure 2. Acceptance of climate change by independent variable.

Table 1. Determinants of coastal stakeholder acceptance of the reality of climate change.

\begin{tabular}{lll}
\hline & Coefficient & Probability \\
\hline Institution Type & & \\
Professional Association & $-1.539(1.408)$ & 0.274 \\
City Government & $-\mathbf{2 . 8 9 8}(\mathbf{1 . 3 6 9})$ & $\mathbf{0 . 0 3 4}$ \\
County/Parish Govern. & $\mathbf{- 2 . 9 1 0 ( 1 . 2 3 4 )}$ & $\mathbf{0 . 0 1 8}$ \\
State Government & $\mathbf{- 2 . 2 3 5 ( 1 . 2 0 8 )}$ & $\mathbf{0 . 0 6 4}$ \\
Federal Government & $-0.393(1.385)$ & 0.777 \\
Resource Harvesting Organization & $-1.617(1.667)$ & 0.332 \\
NGO-Broad Environmental Goals & $-0.216(1.404)$ & 0.877 \\
NGO-Specific Environmental Goals & $-2.061(1.371)$ & 0.133 \\
Port Authority & $\mathbf{- 3 . 4 2 0}(\mathbf{1 . 9 4 0})$ & $\mathbf{0 . 0 7 8}$ \\
Profit-Seeking Organization & $\mathbf{- 2 . 4 3 7}(\mathbf{1 . 3 1 6})$ & $\mathbf{0 . 0 6 4}$ \\
\hline Climate Change Knowledge & & \\
Temperature & $1.372(0.958)$ & 0.152 \\
Sea Level & $\mathbf{1 . 5 5 9}(\mathbf{0 . 7 5 8})$ & $\mathbf{0 . 0 4 0}$ \\
\hline Information Source & & \\
Government (non-EPA) & $-0.235(0.581)$ & 0.686 \\
University & $1.056(0.737)$ & 0.152 \\
Popularized Science Sources & $\mathbf{- 1 . 5 9 4 ( \mathbf { 0 . 7 1 6 } )}$ & $\mathbf{0 . 0 2 6}$ \\
NGO-Environmental & $\mathbf{2 . 2 7 5 ( 1 . 1 1 8 )}$ & $\mathbf{0 . 0 4 2}$ \\
Media & $-0.297(0.556)$ & 0.593 \\
\hline
\end{tabular}


Table 1. Cont.

\begin{tabular}{lll}
\hline & Coefficient & Probability \\
\hline Demographics & & \\
Scientific Training & $\mathbf{- 1 . 1 3 5 ( \mathbf { 0 . 5 6 6 } )}$ & $\mathbf{0 . 0 4 5}$ \\
Florida & $-\mathbf{- 1 . 6 5 0 ( 0 . 6 1 4 )}$ & $\mathbf{0 . 0 0 7}$ \\
Louisiana & $-0.755(0.694)$ & 0.277 \\
\hline Cut Point 1 & $-6.486(1.395)$ & \\
Cut Point 2 & $-0.755(0.694)$ & \\
\hline Number of Cases & 146 & 0.0038 \\
Wald Chi & & \\
Pseudo R & & \\
Log Likelihood & 40.91 & \\
\hline
\end{tabular}

Standard errors are in parentheses. Two-tailed test. Statistically significant predictors are in bold ( $p$-value < 0.100). Note: Ordered logit dependent variable was coded such that $0=$ do not accept, $1=$ mixed acceptance, and 2 = fully accept. Positive coefficient estimates indicate increased likelihood of fully accepting climate change.

The results also provide mixed results for $\mathrm{H} 2$. The analysis does indicate that those that rely upon environmental NGOs for information were more likely to fully accept climate change. Meanwhile, those that rely upon popularized science sources were significantly less likely to accept. We were unable to find a significant influence for government publications, university resources, or the media. These results are consistent with what Neuman et al. [14] would expect.

The analysis also finds mixed support for H3. Specifically, these results suggest that there may be an influence within different types of institutions that will influence one's level of acceptance of climate change. Specifically, the data indicates that those that work in city government, county/parish government, state government, a port authority, and profit-seeking organizations were less likely to fully accept climate change. These results are consistent with the expectations outlined by Ostrom [15], and suggest that there may be institutional norms that influence evaluations of climate change. Particularly striking is the prevalence of government employees that exhibit some level of skepticism in some aspects of climate change.

The results of our control variables produce interesting revelations. The data indicates that those with scientific training are less likely to fully accept climate change. This is contrary to our expectation. The analysis also reveals that respondents from Florida were significantly less likely to fully accept climate change than those from Texas. However, respondents from Louisiana were no more, or less, likely to fully accept.

\section{Discussion}

Several implications can be drawn from this project. First, as Figure 2 illustrates coastal stakeholders are generally likely to accept the reality of climate change and the policy prescriptions offered by scientists. Considering the potential impact that climate change could have on these ecosystems, it is not surprising to see that this group is overwhelmingly in this category. We suspect that this is the case for all stakeholders in this issue domain, regardless of location. This rate of full acceptance is certainly higher than what we would find in the general public. 
Second, we find support for the arguments of KDM, which has not been particularly successful in explaining risk perceptions for climate change within the public [9]. Clearly, KDM is still useful for explaining the relationship between knowledge and risk assessments on climate change. Those with knowledge were generally more apt to have views that were congruent with climate scientists. Perhaps our ability to identify knowledge more accurately via the in-depth interviews created the specificity in measurement, a level rarely seen in public opinion surveys, needed to accurately capture this process.

Third, our analysis allows some observations to be drawn concerning how compelling the evidence of climate change might be, and how this affects attitudes. The data suggests that those that had a great deal of knowledge about precipitation and sea levels and their relationship to climate change were more likely to fully accept the reality of climate change. On the other hand, the influence of knowledge about temperatures never reached a statistically significant impact, which suggests that this evidence may not be as compelling as the others despite greater than ninety percent of those with this knowledge fully agreeing. This interpretation would be consistent with research that suggests that the perception of warmer temperatures will influence the likelihood of believing in climate change depending upon if it is warmer or cooler than average in a respondent's state [23].

Moreover, as Kellstedt et al. [8] suggest, media has framed this as a more contentious issue than the scientific community would indicate, and it appears that the majority of this coverage concerns the link between climate change and global temperatures. Hoffman [24] even suggests that this debate is approaching a logical schism. If attitudes toward climate change can be influenced by local temperatures and media emphasize that there is conflict concerning the science between temperatures and climate change, then, with these results, the information about temperatures may not be as compelling, or at the very least, people are confused.

A fourth implication is the indication that information sources matter. Attitudinal studies typically try to ascertain how often someone exposes themselves to news media to determine their ability to obtain information. However, these results suggest that the process is far more complex. Different sources of information can have a different influence on opinion. This is important because extant research [25,26] has found that those who have the greatest trust in the media are most likely to be influenced through framing, priming, and agenda setting. It is likely that stakeholders are selecting their information sources based upon their trust in those sources, which would be consistent with Lupia and McCubbins [27] contention that people will only gather information when it helps them "avoid costly mistakes" because using untrustworthy information runs counter to this goal [27] (p. 6).

Fifth, the data provides additional evidence that membership in institutions may influence public opinion. By categorizing the micro-level institutions into macro-level institutional groupings, the results reveal that there may be macro-level norms that need to be considered in attitudinal research. These results also indicate that on many issues, it may be important to control for macro-level institutional influences. Many public opinion polls regularly ask questions regarding employment. Rarely is this information modeled, presumably because there is little theoretical justification to do so. However, these results suggest that if we were to collapse these lists into similar types of institutions, then we may be able to tap into macro-level norms that could influence opinion. For instance, consider the possibility that the norms of people who work in construction in some manner (e.g., carpenters, electricians, plumbers, etc.) could cause these individuals to view some issues differently, as a collective group, than 
service industry employees (e.g., wait staff, cooks, delivery drivers, etc.). We hope that our findings will encourage future scholars to consider controlling for these macro-level institutional norms.

It is notable that stakeholders in lower levels of government were less likely to fully accept climate change. In the United States, there is a great deal of decentralization of authority and powers. Indeed, state governments have been far more active in regulating industry with climate change in mind than the national government [28]. The appearance is that if the United States is ever going to act on climate change, it will be up to the states to take that first step. State, local, and county level institutions often have direct influence on, or contact with, state agencies that would draft regulations, and these results suggest that institutional norms within these institutions may serve as impediments to state action. If true, these norms will need to be changed before state action is common. These institutional influences are likely found beyond the United States as well.

A final implication is that non-scientists with scientific training are less likely to fully accept the scientific position on climate change despite the scientific consensus [3,4]. In many ways this seems counterintuitive. A possible explanation is that those who received scientific training were taught to be skeptical about new ideas. For instance, no matter how many times the scientific community found evidence to support Newton's theory of gravity, there was always healthy skepticism that it was always true in every circumstance, which is why it was never declared a Law. Eventually, Einstein unveiled his theory of general relativity, which replaced Newton's theory of gravity as dogma, but it too has never been declared a Law. It is possible that non-scientists with scientific training may remember examples like this. Obviously, this is beyond the scope of this project, but additional research ought to be performed to better understand this relationship.

Finally, we would like to take a moment to discuss the clear shortcoming of this analysis. While we would have liked to have been able to collect basic demographic information, we were unable to do so. Many will dismiss the results of this analysis based simply on this concern. We believe that this would be a mistake. Although these results are far from definitive, they offer a first look at what may be significant predictors of stakeholder climate acceptance. Importantly, the influence of knowledge is frequently found [9] even if it is in an unexpected direction [8] or difficult to interpret [29], in studies of climate risk perceptions. This influence in found even with controls for basic demographics. Consequently, there is reason to believe that the knowledge findings reported here would be found even if we controlled for demographics.

Perhaps more importantly, since this project examines many unique predictors of climate change acceptance, there is little to no research that indicates that individuals of certain groups are more or less likely to belong (e.g., women being more likely to be knowledgeable about sea levels and climate change). While it is possible that conservatives may be more likely to be represented in a profit-seeking organization, there is no reason to believe that any particular type of individual (based on gender, race, income, etc.) would be more likely to belong to many of the other organizations (e.g., state government, port authority, or a professional organization). Mostly, the existing research does not evaluate institutional affiliation, information sources, or knowledge in the manner examined in this project. While we cautiously endorse the results found here, we are more interested in reporting that these relationships may exist in the hope that future research can examine these characteristics within the proper context. Regardless, the fact that there is no clear relationship between the omitted demographic indicators and 
almost all of the variables in the analysis suggests that most of these relationships should be found even if the demographics were included. In any event, future research needs to examine this more closely.

\section{Acknowledgments}

This material is based upon research supported by the U.S. Environmental Protection Agency's National Center for Environmental Assessment/Global Change Research Program under Cooperative Agreement No. R-83023601-0.

It is a joint project of Texas A\&M University's Institute for Science, Technology and Public Policy in The Bush School of Government and Public Service, the Center for Hazards Assessment, Response and Technology at University of New Orleans, the Center for Socioeconomic Research at the University of Louisiana at Lafayette, and the Environmental Sciences Institute at Florida A\&M University.

Any opinions, findings, and conclusions or recommendations expressed in this material are those of the author(s) and do not necessarily reflect the views of the U.S. Environmental Protection Agency.

\section{Author Contributions}

James W. Stoutenborough drafted the theory and discussion sections of the paper and was responsible for the analytical strategy and Arnold Vedlitz was responsible for overseeing the data collection process and instrument development. He also contributed to the theory and discussion sections.

\section{Conflicts of Interest}

The authors declare no conflict of interest.

\section{References}

1. IPCC (Intergovernmental Panel on Climate Change). Climate Change 2014: Impacts, Adaptation, and Vulnerability. IPCC, 2014. Available online: http://www.ipcc.ch/report/ar5/wg2/ (accessed on 12 November 2015).

2. Kreppel, A. Understanding the European Parliament from a federalist perspective: The legislatures of the USA and EU compared. In Comparative Federalism: The European Union and the United States; Schain, M., Menon, A., Eds.; Oxford University Press: New York, NY, USA, 2006; pp. 245-274.

3. Oreskes, N. Beyond the ivory tower: The scientific consensus on climate change. Science 2004, 306, 1686.

4. Rosenberg, S.; Vedlitz, A.; Cowman, D.F.; Zahran, S. Climate change: A profile of U.S. climate scientists' perspectives. Clim. Chang. 2010, 101, 311-329.

5. Collins, H.M.; Evans, R. The third wave of scientific studies: Studies of expertise and experience. Soc. Stud. Sci. 2002, 32, 235-296.

6. Stoutenborough, J.W.; Bromley-Trujillo, R.; Vedlitz, A. Public support for climate change policy: Consistency in the influence of values and attitudes over time and across distinct policy alternatives. Rev. Policy Res. 2014, 31, 555-583.

7. Hansen, J.; Holm, L.; Frewer, L.; Robinson, P.; Sandøe, P. Beyond the knowledge deficit: Recent research into lay and expert attitudes to food risks. Appetite 2003, 41, 111-121. 
8. Kellstedt, P.M.; Zahran, S.; Vedlitz, A. Personal efficacy, the information environment, and attitudes toward global warming and climate change in the United States. Risk Anal. 2008, 28, 113-126.

9. Stoutenborough, J.W.; Vedlitz, A. The Effect of perceived and assessed knowledge of climate change on public policy concerns: An empirical comparison. Environ. Sci. Policy 2014, 37, $23-33$.

10. Kasperson, R.E.; Renn, O.; Slovic, P.; Brown, H.; Emel, J.; Gobble, R.; Kasperson, J.; Ratick, S. The social amplification of risk: A conceptual framework. Risk Anal. 1988, 8, 177-187.

11. Leiserowitz, A. Communicating the risks of global warming: American risk perceptions, affective images and interpretive communities. In Creating a Climate for Change: Communicating Climate Change and Facilitating Social Change; Moser, S.C., Dilling, L., Eds.; Cambridge University Press: Cambridge, UK, 2007; pp. 44-63.

12. Stoutenborough, J.W.; Vedlitz, A.; Liu, X. The Influence of specific risk perceptions on public policy support: An examination of energy policy. Ann. Am. Acad. Political Soc. Sci. 2015, 658, 102-120.

13. Kempton, W. How the public views climate change. Environ. Sci. Policy Sustain. Dev. 1997, 30, $12-21$.

14. Neuman, W.R.; Just, M.R.; Crigler, A.N. Common Knowledge: News and the Construction of Political Meaning; University of Chicago Press: Chicago, IL, USA, 1992.

15. Ostrom, E. Institutional rational choice: An assessment of the institutional analysis and development framework. In Theories of the Policy Process, 2nd ed.; Sabatier, P.A., Ed.; Westview Press: Boulder, CO, USA, 2007; pp. 21-64.

16. Blomquist, W.; Schlager, E.; Heikkila, T. Common Waters, Diverging Streams: Linking Institutions and Water Management in Arizona, California, and Colorado; Resources for the Future: Washington, DC, USA, 2004.

17. Gibson, C.; Williams, J.; Ostrom, E. Local enforcement and better forests. World Dev. 2005, 33, 273-284.

18. Allen, B. Tocqueville, Covenant, and the Democratic Revolution: Harmonizing Earth with Heaven; Lexington Books: Lanham, MD, USA, 2005.

19. Sawyer, A. Beyond Plunder: Toward Democratic Governance in Liberia; Lynne Rienner: Boulder, CO, USA, 2005.

20. Wright, D.S. Understanding Intergovernmental Relations, 3rd ed.; Brooks-Cole: Pacific Grove, CA, USA, 1988.

21. Klinger, D.E. Public Administration: A Management Approach; Houghton Mifflin: Boston, MA, USA, 1983.

22. Vedlitz, A.; Alston, L.T.; Laska, S.B.; Gramling, R.B.; Harwell, M.A.; Worthen, H.D. Use of Science in Gulf of Mexico Decision Making Involving Climate Change; EPA Cooperative Agreement: R-83023601-0; Institute for Science, Technology and Public Policy, The Bush School of Government and Public Service, Texas A\&M University: College Station, TX, USA, 2007.

23. Borick, C.P.; Rabe, B.G. A reason to believe: Examining the factors that determine individual views on global warming. Soc. Sci. Q. 2010, 91, 777-800. 
24. Hoffman, A.J. Talking past each other? Cultural framing of skeptical and convinced logics in the climate change debate. Organ. Environ. 2011, 24, 3-33.

25. Eagly, A.; Chaiken, S. The Psychology of Attitudes; Harcourt Brace Jovanovich: Fort Worth, TX, USA, 1993.

26. Miller, J.M.; Krosnick, J.A. News media impact on the ingredients of presidential evaluations: Politically knowledgeable citizens are guided by a trusted source. Am. J. Political Sci. 2000, 44, 301-315.

27. Lupia, A.; McCubbins, M.D. The Democratic Dilemma: Can Citizens Learn What They Need to Know?; Cambridge University Press: Cambridge, UK, 1998.

28. Matisoff, D.C. The adoption of state climate change policies and renewable portfolio standards: Regional diffusion or internal determinants? Rev. Policy Res. 2008, 25, 527-546.

29. Malka, A.; Krosnick, J.A.; Langer, G. The association of knowledge with concern about global warming: Trusted information sources shape public thinking. Risk Anal. 2009, 29, 633-647.

(C) 2015 by the authors; licensee MDPI, Basel, Switzerland. This article is an open access article distributed under the terms and conditions of the Creative Commons Attribution license (http://creativecommons.org/licenses/by/4.0/). 